\title{
MODIFIED CULTURE METHODOLOGY FOR SPECIFIC DETECTION OF BLASTOCYSTIS HOMINIS IN STOOL SAMPLES
}

\author{
By
}

MARWA A. HASSAN ${ }^{1 *}$, ENAS M. RIZK ${ }^{1}$, AND RITA M. WASSEF ${ }^{2}$

Department of Parasitology ${ }^{1}$, Faculty of Medicine, Cairo University, and

National Hepatology and Tropical Medicine Research Institute ${ }^{2}$, Cairo, Egypt

( ${ }^{\star}$ Correspondence: mahassan@kasralainy.edu.eg)

\section{Abstract}

Blastocystis hominis provides major challenges for laboratory diagnosis due to its polymorphic nature in wet mounts which can result in confusion with other protozoa, yeast or even fat globules. Studies revealed that simple smears were less sensitive than in vitro cultivation using different media for the detection of B. hominis in stool specimens. Cultures of B. hominis are usually enriched by different types of sera to enhance growth and multiplication of the parasite. The aim of this study is to assess the use of two sera types other than horse serum that is commonly used in culture media for the growth, multiplication and detection of $B$. hominis in examined stool samples and comparing the results with those obtained using horse serum.

Fifty stool samples were collected from patients suffering from different colonic manifestations attending Cairo University Hospitals. The samples were freshly cultured in three different culture media using horse serum (in Jones' medium), donkey serum (as a modification in Jones' medium) and human plasma (in modified Pavlova's medium) in adequate preparations. Cultures were then left for incubation and examined by direct microscopy to detect Blastocystis hominis.

The results showed of 50 stool samples studied, 18 samples (36\%) were positive results for $B$. hominis. The number of positive results obtained by horse serum, donkey serum and human plasma were 13,18and 11 respectively. Paired comparisons were made between each 2 cultures with each culture set as a reference once to detect the most appropriate one for diagnosis. When horse was set as the reference method, donkey serum showed a sensitivity of $100 \%$ and specificity of $86.5 \%$ with a $90 \%$ agreement between the 2 methods. While human plasma showed a sensitivity of $46.2 \%$ and specificity of $86.5 \%$ with an agreement of $76 \%$. In addition, the vacuolar form was the commonest pattern observed in this study throughout all the three cultures.

Key Words: Blastocystis hominis, culture, horse serum, donkey serum, human plasma.

\section{Introduction}

Blastocystis hominis is a rising enteric protozoan with zoonotic potential. It is one of the commonest parasites affecting human gut, with an incidence rate varying between $10 \%$ of the population in the developed countries and $50 \%$ in developing countries (Wong et al, 2008). It is considered as the most common eukaryotic organism reported in human fecal samples (Tan et al, 1997). The capability of $B$. hominis to cause infection is currently a subject of extreme argue. Most of the confusion arises from several clinical and epidemiological studies that either link or free the parasite as a cause for intestinal disease (Tan et al, 2002). However, latest researches proposed that $B$. hominis is pathogenic or related to a variety of intestinal disorders (Barahona et al, 2003; Hailemariam et al, 2004; Cassano et al, 2005; Andiran et al, 2006; Puthia et al, 2008; Duda et al, 2014).

Direct microscopic examination of faecal samples, with or without addition of Lugol's iodine solution, as well as permanent smears stained with trichrome had been recommended for diagnosis of Blastocystis spp. infection (Amato Neto et al.,2003). Blastocystis is a polymorphic protozoan with four main forms being described in literature. The several forms observed within in-vitro culture comprise vacuolar, granular, amoeboid, cyst, avacuolar, multi-vacuolar forms. However, vacuolar, granular, amoeboid and 
cyst are the most commonly observed forms (Barua et al, 2015). Different epidemiological studies for diagnosis of Blastocystis spp. suggested that the Blastocystis spp. multiply rapidly in culture medium enhanced with serum after $24-48 \mathrm{~h}$ of cultivation and considered it the most sensitive method for diagnosis of Blastocystis infection (Nascimento and Moitinho, 2005).

This study was conducted to assess the use of donkey serum and human plasma in addition to horse serum that is commonly used in culture medium, to detect growth, multiplication and diagnosis of $B$. hominis in stool samples, and compare results with horse serum.

\section{Material and Methods}

Study design: This is a cross sectional study aiming to compare between three culture media to detect $B$. hominis in stool samples.

Sample collection and processing: Fifty stool samples were collected from the patients suffering from different colonic manifestations, attending outpatient clinics of Internal Medicine and Tropical Medicine Departments at Kasr-Alainy Teaching Hospital, Cairo University.

All fifty samples were collected in clean, dry, labeled containers and were freshly cultured on three different media, left for incubation for up to 72 hours. Cultures were examined by direct microscopic examination in the Diagnostic and Research Unit of the Medical Parasitology Department, Faculty of Medicine, Cairo University. Stool Samples were examined under both a high power and oil immersion lens (40X \& 100X) of microscope to detect the possible $B$. hominis infection.

Culture preparation: Three different liquid media were used as follows: 1- The first medium (referred to as Horse) is the wellknown Jones' medium with horse serum (Jones, 1946). For preparation; 1.244g of disodium phosphate $\left(\mathrm{Na}_{2} \mathrm{HPO}_{4}\right)$ was dissolved in $131.25 \mathrm{ml}$ distilled water. In another container $0.397 \mathrm{~g}$ of monopotassium phosphate $\left(\mathrm{KH}_{2} \mathrm{PO}_{4}\right)$ was dissolved in $43.75 \mathrm{ml}$ distilled water, and in a third one $7.07 \mathrm{~g}$ of $\mathrm{NaCl}$ was dissolved in $787.50 \mathrm{ml}$ distilled water. The previously mentioned preparations were mixed together giving a total volume of $962.5 \mathrm{ml}$. $12.5 \mathrm{ml}$ from the solution was discarded, so $950 \mathrm{ml}$ was left. In another container, $1 \mathrm{~g}$ of yeast extract was dissolved in $100 \mathrm{ml}$ of the left solution. This $1 \%$ yeast preparation was added back to the remaining of the solution $(850 \mathrm{ml})$. The final volume reaches $950 \mathrm{ml}$ with approximately $0.01 \%$ yeast. The solution was then aliquoted into $100 \mathrm{ml}$ bottles and autoclaved at $121^{\circ} \mathrm{C}$ overnight. Ten $\mathrm{ml}$ of inactivated horse serum was added to $90 \mathrm{ml}$ of the above sterile medium under the UVR-Laminar flow sterilized hood $5 \mathrm{ml}$ of the medium was aliquoted into sterile $7 \mathrm{ml}$ culture tube using sterile pipette and was kept at $-20^{\circ} \mathrm{C}$ until used. 2- The second medium (referred to as donkey) is a new modification to Jone's medium; in which donkey serum was used instead of horse serum to evaluate the ability of $B$. hominis to utilize the components in the donkey serum and grow in this modified medium. The donkey serum was immersed in water bath at $56^{\circ} \mathrm{C}$ to inactivate unwanted enzymes (HyClone, 1996). Culture media was prepared using the same steps used in Jones' medium but using donkey serum instead of horse serum. 3- Third medium (referred to as human) was prepared using human plasma in a slightly modified Pavlova's medium (Zerpa et al, 2000; [sodium acid phosphate $12 \mathrm{H}_{2} \mathrm{O}, 8.95 \mathrm{~g}$; potassium phosphate, $1.15 \mathrm{~g}$; chloride sodium, $20 \mathrm{~g}$; yeast extract, 4g; and distilled water, 2,750mL. Besides, 5\% human plasma was added. Then $2.75 \mathrm{~g}$ of sterile rice starch was added. The medium was distributed in sterile glass tubes, $7 \mathrm{~mL}$ each. Stool was added to all three culture media and was incubated at $37^{\circ} \mathrm{C}$. Samples were examined $24,48 \& 72 \mathrm{~h}$ post culture.

Statistical analysis: Data were analyzed using Statistical Package for Social Sciences (SPSS) version 17 (Chicago, IL, USA). Pos- 
itive rates were expressed as percentages. Paired observations with sensitivities and specificities for each method were calculated.

Ethical considerations: All procedures performed throughout the study involving human participants were in accordance with the ethical standards of ethical committee of Faculty of Medicine, Cairo University and with the 1964 Helsinki Declaration and its later amendments or comparable ethical standards. Participation in the present study was optional and participants or their guardians signed an informed consent for sample collection and subsequent analysis according to national guidelines.

Conflict of Interest: The present authors declare that they have neither competing interests nor reserved financial support

\section{Results}

In the present study B. hominis was detected in 18 out of the 50 stool samples $(36 \%)$. Donkey serum could detect 18 positive samples while horse serum and human plasma detected 13 \& 11 samples respectively. The sensitivity and specificity of each culture medium were different. However, all three assays were in agreement for $70 \%$ of samples (35/50: 6 positive \& 29 negative). Number of samples were either positive ( 0 by horse, 3 by donkey, and 3 by human) or negative ( 2 by horse, 0 by donkey, and 7 by human) by only one of the three assays, distribution of positive and negative results by the three methods for detection of B. homi$n i s$ in Venn diagram (Fig. 1). Among the positive samples, 13 samples were positive by horse serum; which were all also positive by donkey serum and only 6 were positive by human serum. Within the negative samples, 37 samples were negative by the horse serum of which 32 were also negative by donkey serum and 32 by human serum.

The comparative sensitivity and specificity of each of the three methods for detection of B. hominis are presented (Tab. 1). Within each comparison, each method was considered as the reference method (e.g., Horse is compared to donkey once with horse as reference method and once with donkey as reference method). In each of the three comparisons (A: horse vs. donkey; B: horse vs. human and $\mathrm{C}$ : donkey vs. human) both methods served as reference standard.

Table 1: Comparison of sensitivity and specificity of B. hominis detection by three different methods

\begin{tabular}{|c|c|c|c|c|c|c|c|}
\hline \multirow[t]{2}{*}{ A1 } & & \multicolumn{2}{|c|}{ Horse } & & \multirow[t]{2}{*}{$\mathrm{A} 2$} & \multicolumn{2}{|c|}{ Reference } \\
\hline & & Negative & Positive & Total & & Donkey & Horse \\
\hline \multirow[t]{3}{*}{ Donkey } & Negative & 32 & 0 & 32 & Sensitivity & 72.2 & 100 \\
\hline & Positive & 5 & 13 & 18 & Specificity & 100 & 86.5 \\
\hline & Total & 37 & 13 & 50 & & & \\
\hline \multirow[t]{2}{*}{ B1 } & & \multicolumn{2}{|c|}{ Horse } & & \multirow[t]{2}{*}{ B2 } & \multicolumn{2}{|c|}{ Reference } \\
\hline & & Negative & Positive & Total & & Human & Horse \\
\hline \multirow{3}{*}{ Human } & Negative & 32 & 7 & 39 & sensitivity & 54.5 & 46.2 \\
\hline & Positive & 5 & 6 & 11 & specificity & 82.1 & 86.5 \\
\hline & Total & 37 & 13 & 50 & & & \\
\hline \multirow[t]{2}{*}{$\mathrm{C} 1$} & & \multicolumn{2}{|c|}{ Donkey } & & $\mathrm{C} 2$ & \multicolumn{2}{|c|}{ Reference } \\
\hline & & Negative & Positive & Total & & Human & Donkey \\
\hline \multirow[t]{3}{*}{ Human } & Negative & 29 & 10 & 39 & sensitivity & 72.7 & 44.4 \\
\hline & Positive & 3 & 8 & 11 & specificity & 74.4 & 90.6 \\
\hline & Total & 32 & 18 & 50 & & & \\
\hline
\end{tabular}

Paired observations (horse vs. donkey, horse vs. human and donkey vs. human) were available for all 50 stool samples. When Horse is compared to Donkey with Horse as the reference method, sensitivity is $100 \%$. Specificity also is high $(86.5 \%)$; alt- hough they agree with each other well $(90 \%)$. When Donkey is used as the reference method in this comparison Horse has a specificity of $100 \%$ \& sensitivity of $72.2 \%$. When horse was compared to human; again, with horse as the reference method, human 
sensitivity was low (46.2\%) and specificity was high $(86.5 \%)$, while, when human was considered the reference standard, horse sensitivity was $(54.5 \%)$ whereas specificity was high $(82.1 \%)$. The overall agreement between the two methods was $76 \%$.

When donkey was compared to human; donkey was set as the reference method, human sensitivity was low (44.4\%) and specificity was high (90.6\%). However, when human was considered as the reference standard, the donkey's sensitivity was $(72.7 \%)$ whereas the specificity was high (74.4\%). The overall agreement between the two methods was $74 \%$. Microscopic examination revealed that the vacuolar form of $B$. hominis was the predominant form detected in the positive samples in the three types of cultures (Fig. 2 A \& B).

\section{Discussion}

Blastocystis spp. have a widespread geographic distribution all over the world (Tan, 2008). Due to insufficient evidence to designate new species of Blastocystis from humans without further biochemical and epidemiological data, B. hominis is the only species of Blastocystis infecting human hosts (Barua et al, 2015). B. hominis is a cosmopolitan protozoon which parasitizes the human large intestine. A positive diagnosis of $B$. hominis infection depends on the presence of vacuolar, granular, or amoebic forms in diarrheic stool, or the detection of the cyst form predominantly in formed feces under light microscopy using wet mount smears, iodine staining, or permanent dye as trichrome staining (Stensvold et al, 2007) or iron hematoxylin staining (Noel et al, 2003). However, the misidentification of Blastocystis with other organisms or even yeasts is a familiar problem and may bewilder studies limited to the use of microscopy alone (Stark et al, 2006). In addition, the organism might also be present in low numbers in the tested stool samples (Suresh and Smith, 2004).

In order to gain more sensitive diagnostic tool, in vitro cultivation of fresh specimens for this protozoan prior to light microscopy has been described and widely used (Zierdt, 1991, Clark and Diamond, 2002; Suresh and Smith, 2004; Tan, 2004; 2008). Most of these culture media require addition of serum for animals or humans and contain different types of salts and other materials. Moreover, culture techniques are more cost-effective and need less expertise to perform than those of molecular biological and immunological techniques for the laboratory diagnosis (Termmathurapoj et al, 2004; Su et al, 2007).

There are many types of cultures used for this parasite detection such as Jones' solution medium (Jones, 1946), Loffler medium, ringer solution medium (Stenzel and Boreham, 1996), modified whole-egg Slant medium, Locke solution (Zierdt, 1991), Xenic culture (Dogruman-Al et al, 2010) and methods made by Zerpa et al. (2000) who made a new culture modification in Pavlova's medium using human plasma. Saksiris ampant et al. (2010) deduced that Locke egg medium (LE medium) has the advantage of lower cost than that of the Jones' medium. Since the hen egg consisting in LE medium is cheaper than yeast extract, which must be imported. Moreover, they stated that hen egg could eliminate concerns about expiration dates of yeast extracts. Barua et al. (2015) reported that Xenic culture could be good medium but it contained many substances. Many studies used Jones medium successfully as the choice medium to culture Blastocystis. (Leelayoova et al, 2002; Suresh and Smith, 2004; Parker et al, 2007).

In the present work, in vitro culture using three different culture media was employed to detect which medium could be more successfully used to diagnose $B$ hominis in stool samples according to the obtained results. The media used included Jones' medium using Horse serum, Jones' medium using Donkey serum as a modification of the procedure and finally human plasma in a slightly modified Pavlova's medium (Zerba et al, 
2000). All three culture media were incubated and examined by direct microscopy.

Fifty stool samples were collected from patients suffering from GIT manifestations attending to Cairo University Hospitals and were freshly cultured on the three media types. The results revealed that $36 \%$ of the samples were positive for B. hominis. A similar study was done to investigate the presence of $B$ hominis in persons with GIT symptoms in Sydney and showed a percentage of 19\% (Roberts et al, 2011). Also, studies from Germany, Thailand, and China reported incidences of $17.9 \%, 13.3 \%$, and 32.6\%, respectively (Yoshikawa et al, 2004; Li et al, 2007). These lower values than the present data might be attributed to the fact that all these countries are considered as developing countries with adequate personal hygiene, proper environmental sanitation and satisfactory health awareness. However, the attendees of Cairo University Hospitals usually come from peri-urban or rural areas of high population densities and low socioeconomic class populations aiding in protozoa transmission. On the other hand other studies have reported Blastocystis in much higher frequencies in which results were obtained on the basis of microscopy only $53.8 \%$ in Zambia (Graczyk et al, 2005), $52.3 \%$ in Malaysia (Noor Azian et al, 2007) and $30 \%$ in travelers in Nepal (Sohail and Fischer, 2005). These high frequencies may be accredited to the misidentification of Blastocystis with other organisms such as cysts or trophozoites of other protozoa, yeast or even fat cells, or may be due to low number of organisms in the sample (Stark et al, 2006; Suresh and Smith, 2004).

The current study revealed that the vacuolar form was the most common form found throughout all three types of culture media used. This agreed with Abdel Hafez et al. (2015) and Zhang et al. (2007) who stated that the vacuolar form was the typical Blastocystis cell form, and it was the most regularly used microbiological evidence for diagnosis of Blastocystis spp. infection.
Abu El Naga and Negm (2001) reported that the cyst forms of Blastocystis spp. were found chiefly in fecal maters stored for several days before being fixed. Granular forms mostly appear in older cultures of isolates or might be due to increased serum in culture media (Soriano et al, 2001; Katsarou-Katsari et al, 2008).

In this study, although each medium showed different sensitivity and specificity yet, they were all in agreement in $70 \%$ of the samples. Paired observations were offered for all samples so that within each comparison each method was considered as the reference method once. This was actually necessary since Horse serum in Jones' medium is still considered the 'gold standard', however its sensitivity and specificity for $B$. hominis detection is still imperfect i.e. not 100\% each (Poirier et al, 2011; Elghareeb et al, 2015)

When horse serum was compared to donkey serum with horse serum as the reference method, sensitivity was perfect $(100 \%)$, indicating that donkey serum detects all positive cases detected by horse serum. Specificity was also high $(86.5 \%)$. Both sera types showed agreement in $90 \%$ of the samples. When the donkey serum was the one used as the reference horse serum gave a specificity $(100 \%)$ and sensitivity $(72.2 \%)$.

On comparing horse serum with human serum with each one as the reference once, the results indicated that interchanging the reference methods here had little effect on the sensitivities $(46.2 \%$ \& $54.5 \%$ for human and horse serum respectively) and specificities $(86.5 \%$ \& $82.1 \%$ for human and horse serum respectively) obtained thus deducing that both methods were similarly sensitive and specific for $B$. hominis detection with an overall agreement of $76 \%$. On comparing donkey serum with human serum, there was a low sensitivity(44.4\%) but a high specificity $(90.6 \%)$ of human serum indicating that its use couldn't detect all positive samples that were detected by donkey serum. 
To the best of the present knowledge this is the first study in literature to use donkey serum in a culture medium for the growth and multiplication of $B$ homins. This proximity in sensitivity, specificity in addition to overall agreement obtained by both horse and donkey sera could attract our attention to the use of donkey serum as an alternative to horse serum in the culture media used for diagnosis of this protozoan. Also, the obvious morphological pattern was obtained by the donkey serum which was not at all less clear than those obtained by horse serum medium. This was not much astonishing as both animals belong to the equines which make them liable to share similar biological and biochemical features. Actually speaking, the use of donkey serum in research laboratories could be of great value especially in developing countries and in donkey rearing countries where this method could be cost effective and easy to use. Unlike horses, donkeys can thrive on very marginal forage, which makes them very economical to keep. Human plasma in culture medium by Zerba et al. (2000) showed B. hominis in $70 \%$ of stool samples vs. $21 \%$ with wet mount examination. This method was cost-effective as neither required horse serum nor an aerobiotic system and recommended an alternative to known standard methods. The present study showed lower sensitivities and specificities when compared to other 2 procedures when set as reference methods.

\section{Conclusion}

The results propose the use of donkey serum as good alternative to horse serum in culture media for Blastocystis hominis. Donkey serum could be preferably used in developing countries where donkeys are commonly bred, of less economic burden and much more available than horses. Modified Pavlova's medium using human plasma showed lower sensitivities and specificities when compared to the other 2 media.

\section{Recommendations}

Other types of animal sera could also be used in other studies for detection of this protozoan. Additional studies may be needed to detect which type of culture becomes positive more quickly for feasible identification after 24 hours. Also, since protozoan infection can be an indicator of poor personal and community hygiene, improvement of sanitation is crucial to prevent, not only $B$. hominis but also for other intestinal protozoa.

\section{Acknowledgment}

The authors would like to thank D. Abdelbary Mohammed Prince, Biochemistry Department, Faculty of Veterinary Medicine, Cairo University for his great help in providing the donkey serum used in this study.

\section{References}

Abdel-Hafeez, EH, Ahmad, AK, Abdelgelil, N H, Abdellatif, MZ, Kamal, AM, Mohamed, R M, 2015: In vitro effect of some Egyptian herbal extracts against Blastocystis hominis. J. Egypt. Soc. Parasitol. 45, 1:93-100.

Abou EI Naga IF, Negm AY, 2001: Morphology, histochemistry and infectivity of Blastocystis hominis cyst. J. Egypt. Soc. Parasitol. 31:62735 .

Amato Neto, V, Rodríguez Alarcón, RS, Gakiya, E, Bezerra, RC, Ferreira, CS, et al, 2003: Blastocystosis: controversy and indefinedness. Rev. Soc. Bras. Med. Trop. 36:515-7

Andiran, N, Acikgoz, ZC, Turkay, S, Andiran, F, 2006: Blastocystis hominis-an emerging and imitating cause of acute abdomen in children. J. Pediatr. Surg. 41, 8:1489-91.

Barahona, RL, Maguina, VC, Naquira, VC, Terashima, IA, Tello, R, 2003: Human blastocystosis: Prospective study symptomatology and associated epidemiological factors. Rev. Gastroenterol. Peru 23:29-35.

Barua, P, Khanum, H, Najib, F, Kabir, M, 2015: Establishment of Blastocystis hominis invitro culture using fecal samples from infants in slum area of Mirpur, Dhaka, Banglandesh. Acta Med. Int. 2, 1:23-8.

Cassano, N, Scoppio, B, Loviglio, M, Vena, G, 2005: Remission of delayed pressure urticaria after eradication of Blastocystis hominis. Acta Derm. Venereol. 85:357-8.

Clark, CG, Diamond, LS, 2002: Methods for cultivation of luminal parasitic protists of clinical importance. Clin. Microbiol. Rev. 15, 3:32941.

Dogruman-Al, F, Simsek, Z, Boorom, K, Eki- 
ci, E, Sahin, M, 2010: Comparison of methods for detection of Blastocystis infection in routinely submitted stool samples, and also in IBS/IBD patients in Ankara, Turkey. PLoS One 5:e15484. Duda, A, Kosik-Bogacka, DN, Szymański, S, 2014: Blastocystis hominis-parasites or commensals? Ann. Acad. Med. Stetin. 60, 1:23-8.

Elghareeb, AS, Younis, MS, El-Fakahany, A F, Nagaty, IM, Nagib, MM, 2015: Laboratory diag-nosis of Blastocystis spp. in diarrheic patients. Trop. Parasitol. 5, 1:36-41.

Graczyk, TK, Shiff, CK, Tamang, L, Munsaka, F, Beitin, AM, et al, 2005: The association of Blastocystis hominis and Endolimax nana with diarrheal stools in Zambian school-age children . Parasitol. Res. 98:38-43.

Hailemariam, G, Kassu, A, Abebe, G, Abate, E, Damte, D, et al, 2004: Intestinal parasitic infections in HIV/AIDS and HIV seronegative individuals in a teaching hospital, Ethiopia. Jpn. J. Infect. Dis. 57:41-3

HyClone, 1996: Cell culture notes: Art to Science. Vol. 15, 1:1-5.

Jones, DR, 1946: A medium for investigating the breakdown of pectin by bacteria. Nature 158, 4018:625.

Katsarou-Katsari, A, Vassalos, CM, Tzanetou, K, Spanakos, G, Papadopoulou, C, et al, 2008: Acute urticaria associated with amoeboid forms of Blastocystis sp. subtype 3. Acta Derm. Venereol. 88:80-1.

Leelayoova, S, Taamasri, P, Rangsin, R, Naaglor, T, Thathaisong, $\mathrm{U}$, et al, 2002: In-vitro cultivation: a sensitive method for detecting Blastocystis hominis. Ann. Trop. Med. Parasitol. 96:803-7.

Li, LH, Zhou, XN, Du, ZW, Wang, XZ, Wang, LB, et al 2007: Molecular epidemiology of human Blastocystis in a village in Yunnan Province, China. Parasitol. Int. 56:281-6.

Nascimento, SA, Moitinho, MLR, 2005: Blastocystis hominis and other intestinal parasites in a community of Pitanga city, Parana state, Brazil. Rev. Inst. Med. Trop. São Paulo 47:213-7.

Noel, C, Peyronnet, C, Gerbod, D, Edgcomb, VP, Delgado-Viscogliosi, $P$, et al 2003: Phylogenetic analysis of Blastocystis isolates from different hosts based on the comparison of smallsubunit rRNA gene sequences. Mol. Biochem. Parasitol. 126:119-23.

Noor Azian, MY, San, YM, Gan, CC, Yusri, MY, et al, 2007: Prevalence of intestinal proto- zoa in an aborigine community in Pahang, Malaysia. Trop. Biomed. 24:55-62.

Parkar, U, Traub, RJ, Kumar, S, Mungthin, M, Vitali, S, et al, 2007: Direct characterization of Blastocystis from faeces by PCR and evidence of zoonotic potential. Parasitology 134:35967.

Poirier, P, Wawrzyniak, I, Albert, A, Alaoui, HE, Delbac, F, Livrelli, V, 2011: Development and evaluation of a real-time PCR assay for detection and quantification of Blastocystis parasites in human stool samples: prospective study of patients with hematological malignancies. J. Clin. Microbiol. 49:975-83.

Puthia, MK, Lu, J, Tan, KS, 2008: Blastocystis ratti contains cysteine proteases that mediate interleukin-8 response from human intestinal epithelial cells in an NF-kappaB-dependent manner. Eukaryot Cell.7:435-43.

Roberts, T, Barratt, J, Harkness, J, Ellis, J, Stark, D, 2011: Comparison of microscopy, culture, and conventional polymerase chain reaction for detection of Blastocystis sp. in clinical stool samples. Am. J. Trop. Med. Hyg. 84:308-12. Saksirisampant, W, Nuchprayoon, S, Pradniwat, P, Lamchuan, D, 2010: Boeck and Drbohlav Locke egg serum medium for detection of Blastocystis hominis. Chula Med. J. 54, 6:52736.

Sohail, MR, Fischer, PR, 2005: Blastocystis hominis and travelers. Travel Med. Infect. Dis. 3:33-8.

Soriano, SV, Barbieri, LM, Pierángeli, NB, Giayetto, AL, Manacorda, AM, et al, 2001: Intestinal parasites and the environment: Frequency of intestinal parasites in children of Neuquén, Patagonia, Argentina. Rev. Latinoam Microbiol. 43:96-101

Stark, DJ, Beebe, N, Marriott, D, Ellis, JT, Harkness, J, 2006: Dientamoebiasis: Clinical importance and recent advances. Trends Parasitol. 22:92-6.

Stensvold, CR, Arendrup, MC, Jespersgaard, C, Molbak, K, et al, 2007: Detecting Blastocystis using parasitologic and DNA-based methods: a comparative study. Diagn. Microbiol. Infect. Dis. 59:303-7.

Stenzel, D, Boreham, P, 1996: Blastocystis hominis revisited. Clin. Microbiol. Rev. 9:563-84.

Su, SL, Yan, YM, Liao, H, Chen, GF, Zhang, RQ, et al, 2007: Dot enzyme-linked immunosorbent assay for detection of serum antibody to 
Blastocystis hominis in humans. Zhongguo Ji Sheng Chong Xue Yu Ji Sheng Chong Bing Za Zhi. 25, 3:256-8.

Suresh, K, Smith, H, 2004: Comparison of methods for detecting Blastocystis hominis. Eur. J. Clin. Microbiol. Infect. Dis. 23:509-11.

Tan, KS, 2004: Blastocystis in humans and animals: New insights using modern methodologies. Vet. Parasitol. 126, 1/2:121-44

Tan, KS, 2008: New insights on classification, identification, and clinical relevance of Blastocystis spp. Clin. Microbiol. Rev. 21, 4:639-65.

Tan, SW, Singh, M, Ho, LC, Howe, J, 1997: Survival of Blastocystishominis clones after exposure to a cytotoxic monoclonal antibody. Int. J. Parasitol; 27: 947-954.

Tan, KSW, Singh, M, Yap, EH, 2002: Recent advances in Blastocystis hominis research: hot spots in terra incognita. Int. J. Parasitol. 32:789804.

Termmathurapoj, S, Leelayoova, S, Aimpun, $P$, Thathaisong, $U$, Nimmanon, $T$, et al, 2004:
The usefulness of short-term in vitro cultivation for the detection and molecular study of Blastocystis hominis in stool specimens. Parasitol. Res. 93, 6:445-7.

Wong, KH, Ng, G, Lin, R, Yoshikawa, H, Taylor, M, et al, 2008: Predominance of subtype 3 among Blastocystis isolates from a major hospital in Singapore. Parasitol. Res. 102:663-70.

Yoshikawa, H, Wu, Z, Kimata, I, Iseki, M, Ali, IK, et al, 2004: Polymerase chain reactionbased genotype classification among human Blastocystis hominis populations isolated from different countries. Parasitol. Res. 92:22-9.

Zerpa, L, Huicho, L, Naquira, C, et al, 2000: A simplified culture method for Blastocystis hominis. Rev. Mex. Patol. Clin. 47. 1:17-9.

Zhang, X, Qiao, JY, Zhou, XJ, Yao, FR, Wei, ZC, 2007: Morphology and reproductive mode of Blastocystis hominis in diarrhea and in vitro. Parasitol. Res.101:43-51.

Zierdt, CH, 1991: Blastocystis hominis: Past and future. Clin. Microbiol. Rev. 4, 1:61-79.

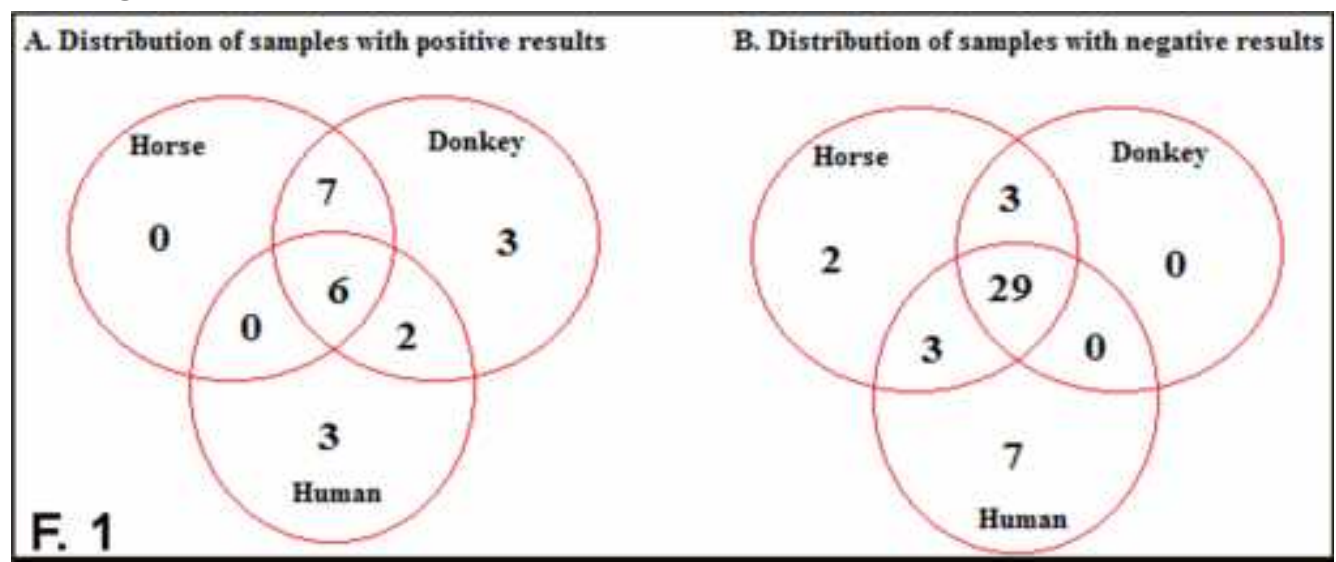

Fig 1: Venn diagram comparing results from horse, donkey, and human media for detection of $B$. hominis.

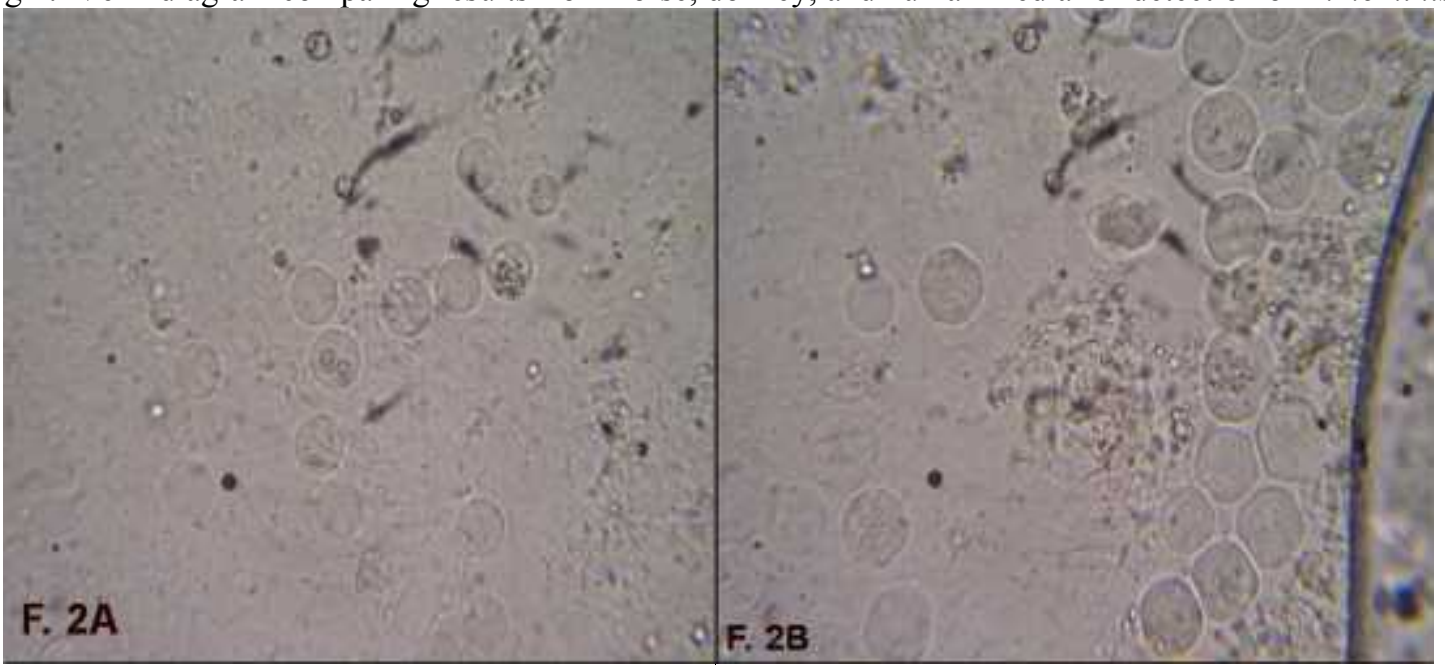

Fig 2: Light microscopy of $B$. hominis showing predominance of vacuolar forms in (A) horse serum enriched culture and (B) donkey serum enriched culture (40X). 